\title{
An Empirical Investigation on Consumer Acceptance of Mobile Banking Services
}

\author{
Bong-Keun Jeong ${ }^{1} \&$ Tom E Yoon ${ }^{1}$ \\ ${ }^{1}$ Department of Computer Information Systems, Metropolitan State University of Denver, Campus Box 45, PO box \\ 173362, Denver, CO 80217, United States \\ Correspondence: Bong-Keun Jeong, Department of Computer Information Systems, Metropolitan State University of \\ Denver, Campus Box 45, PO box 173362, Denver, CO 80217, United States. Tel: 1-303-556-6347. E-mail: \\ bjeong@msudenver.edu
}

Received: October 14, 2012

Accepted: November 9, 2012

Online Published: January 7, 2013

doi:10.5430/bmr.v2n1p31

URL: http://dx.doi.org/10.5430/bmr.v2n1p31

\begin{abstract}
This study explores factors influencing adoption of mobile banking. Based on extended Technology Acceptance Model (TAM), we identified five factors which influence consumers' behavioral intention to adopt mobile banking: perceived usefulness, perceived ease of use, perceived credibility, perceived self-efficacy, and perceived financial cost. Data was collected from 165 respondents through a survey questionnaire, and the regression was used to analyze the relationships. Our results indicate that all factors except for perceived financial cost have a significant impact on behavioral intention towards mobile banking usage. Perceived usefulness is the most influential factor explaining the adoption intention. We also found that consumers' perceptions are different between mobile banking users and non-users. For users, perceived ease of use is the important factor while perceived self-efficacy significantly influence non-users' adoption intention. Implications from these findings help banking institutions to strategically frame their service model for broader mobile banking adoption.
\end{abstract}

Keywords: Mobile Banking, Adoption, Technology Acceptance Model (TAM), Singapore

\section{Introduction}

With rapid advance of Internet technologies and diffusion of mobile phones, mobile banking (hereafter m-banking) has gained attention as a viable option in delivering financial services. M-banking provides financial transactions services such as balance check, fund transfer, and bill payment via a mobile device such as cell phone, PDA, and smart phone (Sripalawat, Thongmak and Ngarmyarn, 2011). In seeking improvements in customer experience, banking institutions have begun offering various m-banking services. According to the TNS mobile life survey, new m-banking users in countries like China, Brazil, and Kenya has increased dramatically. For instance, percentage of Chinese consumers using m-banking increased from $10 \%$ in 2010 to $25 \%$ in 2011 , and increased from $6 \%$ to $18 \%$ in Kenya. This growth, however, is not limited to those developing nations. Countries such as UK, USA, and Sweden also have experienced a reasonable growth (Cellular-News, 2011).

From a managerial point of view, m-banking provides new cost-saving opportunities for banks. Benefits include reducing operation costs, minimizing transaction errors and potential for fraud, generating additional revenue through commissions and service fees, and improving customer retention and brand loyalty (Luo, Li, Zhang and Shim, 2010). While m-banking grows in popularity, mobile transactions have not been used as much as expected (Kleijnen, Wetzels and Ruyter, 2004; Suoranta and Mattila, 2004). There are only 200 million m-banking users out of 5 billion mobile users around the world. Even within developed countries where mobile devices have become almost ubiquitous, m-banking adoption rate is still low (UK - 20.4\%, USA - 22\%, Sweden - 20\%) (Cellular-News, 2011). Consumer skepticism about m-banking is mainly driven by security concerns, financial burdens, and poor accessibility due to handsets and/or wireless network (Kim, Shin and Lee, 2009; Laforet and Li, 2005).

In this study, we focus on a comprehensive set of potential determinants that influence the adoption of m-banking. Five factors, based on extended Technology Acceptance Model (TAM), were considered to examine consumers' behavioral intention to adopt mobile banking: perceived usefulness, perceived ease of use, perceived credibility, perceived self-efficacy, and perceived financial cost. By explaining the behavioral intentions from a user's perspective, the findings of this research not only helps financial institutions to develop a more user-accepted 
m-banking system, but also provides insight into the best way to promote new systems to potential users. We chose to survey the Singapore market for following reasons. Asian countries currently account for more than half of global m-banking users, and are the fastest growing market (Wilcox, 2010). And Singapore has one of the highest mobile population penetration rate $(143.6 \%$ - total number of active mobile subscription divided by total population) compared to other Asian countries (IDA, 2011). A better understanding of factors that influence m-banking adoption in highly developed market like Singapore may help to further increase the adoption rates in countries with improving infrastructures and economies. The rest of this paper is organized as follows. Section 2 presents relevant literature in the area of consumer behavior in the acceptance of m-banking. Section 3 provides the theoretical foundation of our research model, and Section 4 outlines the research methodology. Section 5 presents the results of data analysis, and Section 6 contains managerial implications, conclusions, and directions for future research.

\section{Literature Review}

There is a growing body of academic research examining the determinants of m-banking acceptance and its utilization (Crabbe, Standing, Standing and Karjaluoto, 2009; Donner and Tellez, 2008; Gu, Lee and Suh, 2009; Luarn and Lin, 2005; Mattila, 2003; Riquelme and Rios, 2010). Studies have been conducted in various countries to better understand consumers' attitudes toward this emerging mobile technology. For example, Mattila (2003) focused on the drivers and inhibitors of m-banking services. The author found that complexity, compatibility, relative advantage, observability, and trialability are the significant factors influencing consumer decision making in $\mathrm{m}$-banking adoption. Also, security and confidentiality of information are fundamental pre-requisites for any m-banking services to be successful.

While Mattila primarily focused on Finnish market which was already gearing up for m-banking, Luarn and Lin (2005) conducted a survey in Taiwan where mobile banking was still at an infant stage. The traditional Technology Acceptance Model (TAM) framework was extended by adding one trust-based construct (perceived credibility) and two resource-based constructs (perceived self-efficacy and perceived financial cost) in m-banking context. They found that all factors have a significant effect on behavioral intention, and the perceived credibility is the most contributing factor to intention. Later, the authors extended their study to mobile-service (m-service) context to validate whether their earlier m-banking acceptance model can be generalized to investigate overall $\mathrm{m}$-service acceptance (Wang, Lin and Luarn, 2006). M-service includes a set of chargeable B2C m-service transactions managed by a telecommunication company such as e-mail access, online games, stock trading, mobile shopping, and music/graphics/animation downloads. They showed that all factors considered were significant, but perceived usefulness contribute more to behavioral intention than perceived ease of use, perceived credibility, self-efficacy, and perceived financial resources in the context of $\mathrm{m}$-service.

Mobile payment (m-payment), an integral component of mobile banking, is one which eliminates any movement of physical currency and facilitates the quick payment mode. Cheong and Park (2008) examined the reluctance factors of Koreans to use mobile banking for m-payment. In addition to the traditional TAM factors, they included two additional factors: facilitating conditions and switching barriers. Facilitating conditions refer to the lack of interoperability and market de-facto, and switching barriers refer to high switching costs, and attractiveness of alternatives. The results indicate that facilitating conditions are positively related to the intention to use m-payment while switching barriers are negatively related. Another study by Gu et al. (2009) investigated the determinants of behavioral intention to mobile banking in Korea. The authors proposed an integrated model by introducing trust as another key construct of behavioral intention. In addition, self-efficacy, social influence, facilitating conditions, system quality, familiarity with bank, situational normality, structural assurances, and calculated-based trust were introduced as determinants of key constructs. They found that perceived usefulness is the most important construct to explain the behavioral intention. Also, all the determinants except for familiarity with bank were found to be significant to measure key constructs.

Another stream of research on m-banking is to understand the socio-economic and technological impacts of m-banking adoption in developing countries. For consumers in developed countries, m-banking can be a complementary service (additional platform for managing financial transactions) offered by financial institutions in addition to ATMs and Internet banking. Therefore, factors such as convenience and ease of use may become an importance criteria when they consider adopting m-banking. However, consumers in the developing countries, the appeal of m-banking may be less about convenience, but more about accessibility and affordability due to network coverage, quality connection, and costs (Donner and Tellez, 2008). For example, Laforet and Li (2005) investigated consumer behavior, attitude, motivation, and cultural influence on online/mobile banking adoption in China. Their findings suggest that there are large discrepancies between China and western countries in terms of users' 
demographic characteristics and attitudes towards online/mobile banking. Perceived risks (hackers and fraud) and technological skills were the most important factor influencing Chinese adoption of online and mobile banking. However, consumers in China do not attach much importance on convenience, ease of use, and free access to a wide range of services.

A study by Sripalawat et al. (2011) examined positive and negative factors affecting m-banking acceptance in Thailand. Subjective norms, perceived usefulness, perceived ease of use, and self-efficacy were considered as the positive factors, and device barrier, perceived risk, lack of information, and perceived financial cost as the negative factors. They found that the positive factors have more influence than negative factors towards the acceptance of mobile banking. Among the positive factors, subjective norm is the most influential factor in m-banking adoption in Thailand. Crabbe et al. (2009) examined the impact of social and cultural characteristics on m-banking adoption in Ghana. They showed that social and cultural factors in the form of perceived credibility, facilitating conditions, perceived elitisation and demographic factors play an important role in influencing adoption and sustained usage. In addition, perceived credibility and facilitating conditions also influence attitudes towards the technology.

Table 1. Selected Literature on Consumer Acceptance of M-Commerce and M-Banking

\begin{tabular}{|c|c|c|c|c|c|c|c|c|c|c|}
\hline \multirow[b]{2}{*}{ Authors } & \multirow[b]{2}{*}{ Context } & \multirow[b]{2}{*}{ Region } & \multicolumn{8}{|c|}{ Factors considered in the study } \\
\hline & & & 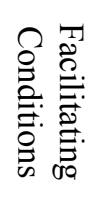 & $\frac{\pi}{\pi}$ & 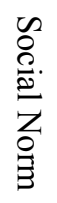 &  & 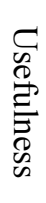 & $\begin{array}{l}\Omega \\
\stackrel{0}{0} \\
\stackrel{\Xi}{\sigma} \\
\stackrel{\Xi}{\Xi}\end{array}$ & 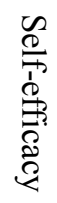 & 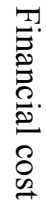 \\
\hline Bhatti & M-commerce & $\mathrm{N} / \mathrm{A}$ & & & $\bullet$ & $\bullet$ & $\bullet$ & & & \\
\hline Crabbe et al. & M -banking & Ghana & - & & & $\bullet$ & $\bullet$ & $\bullet$ & & \\
\hline Sripalawat et al. & M-banking & Bangkok & & $\bullet$ & $\bullet$ & $\bullet$ & $\bullet$ & & $\bullet$ & $\bullet$ \\
\hline Wu and Wang & M-commerce & Taiwan & & $\bullet$ & & $\bullet$ & $\bullet$ & & & $\bullet$ \\
\hline Laurn and Lin & M-banking & Taiwan & & & & $\bullet$ & $\bullet$ & $\bullet$ & $\bullet$ & $\bullet$ \\
\hline Wang et al. & M-service & Taiwan & & & & $\bullet$ & $\bullet$ & $\bullet$ & $\bullet$ & $\bullet$ \\
\hline Cheong et al. & M-payment & Korea & $\bullet$ & & & $\bullet$ & $\bullet$ & & & $\bullet$ \\
\hline Gu et al. & M-banking & Korea & $\bullet$ & & $\bullet$ & $\bullet$ & $\bullet$ & & $\bullet$ & \\
\hline Yang & M-commerce & Singapore & & & & $\bullet$ & $\bullet$ & & & \\
\hline $\begin{array}{l}\text { Riquelme and } \\
\text { Rios }\end{array}$ & M-banking & Singapore & & & $\bullet$ & $\bullet$ & $\bullet$ & & & \\
\hline Our study & M-banking & Singapore & & & & $\bullet$ & $\bullet$ & $\bullet$ & $\bullet$ & - \\
\hline
\end{tabular}

A summary of relevant literature on consumer acceptance of m-banking is shown in Table 1. As the Table shows, some of these adoption factors are common to all studies while others are only used in a particular domain (region). It is also important to note that the significance of factors influencing m-baking adoption varies widely across different countries (Sripalawat, Thongmak and Ngramyarn, 2011). This indicates that consumer acceptance of m-banking is extremely context-dependent, so a particular dimension may not make a significant contribution or not even be applicable depending on the context. This could be due to the peculiar differences in cultures, infrastructural conditions, and economic/political conditions prevailing in different regions.

Few studies have examined m-banking (or m-commerce) adoption factors in Singapore market. For instance, Yang (2005) showed that perceived usefulness and perceived ease of use influence attitude toward using m-commerce. Another study by Riquelme and Rios (2010) examined the factors influencing adoption of m-banking among current users of Internet banking in Singapore. They found that perceived usefulness, social norms, and social risk are the factors that influence the intention to adopt m-banking services. The study also showed that ease of use has a stronger influence on females while relative advantage influences more on perceived usefulness for males. And social norms have a significant role influencing the adoption of $\mathrm{m}$-banking among female respondents than male. However, these two studies are different from ours as it focused on m-commerce in general and biased toward people who are already using Internet banking. Also, they incorporated only a few elements of consumer behavioral intention to adopt m-banking. Adapted from extend TAM, we provide a more comprehensive view of consumer $\mathrm{m}$-banking acceptance by including three additional components: perceived credibility, perceived self-efficacy, and perceived financial cost. 


\section{Research Model and Hypotheses}

Technology Acceptance Model (TAM) is the most commonly used framework to examine factors influencing the adoption of information systems. Originally developed from Fishbein and Ajzen's Theory of Reasoned Action (TRA), TAM examines the factors that influence user's intentions to accept or reject information systems (Wu and Wang, 2005). The model suggests that the user adoption of a new information system is determined by two factors: perceived usefulness and perceived ease of use. Perceived usefulness is defined as the extent to which a person believes that using a particular system will enhance his or her job performance, and perceived ease of use is defined as the extent to which a person believes that using a particular system will be free of effort. These perceptions form the attitude and attitudes develop into intentions which in turn drive the actual system usage.

One of the main reasons for wide acceptance of TAM is due to its specific approach to address the factors that influence usage of information system while TRA is a general theory of human behavior (Mathieson, Peacock, and Chin, 2001). Another reason is its parsimony due to the vast amounts of data and empirical studies conducted that reaffirmed the validity of this theory. TAM has been validated through examining various types of technologies pertinent to individual and organization adoption such as electronic commerce (Pavolu, 2003), intranet (Horton, Buck, Waterson and Clegg, 2001), World Wide Web (Lederer, Maupin, Sena and Zhuang, 2000), and online shopping (Gefen, Karahanna and Straub, 2003). However, prior studies also indicate that one of the limitations of TAM model is the omission of other important variables affect user acceptance such as trust-based construct and resource-based construct. Some constructs were added into the original TAM model to facilitate understanding of the information system adoption (Gefen, Karahanna and Straub, 2003; Wang, Wang, Lin and Tang 2003; Luarn and Lin, 2005). Extended TAM includes these additional constructs as TAM's fundamental constructs don't address certain technological and usage context factors that may also alter the decision making behavior of an individual (Luarn and Lin, 2005). Five factors in Extended TAM are perceived usefulness, perceived ease of use, perceived credibility, perceived self-efficacy, and perceived financial cost. In the following section, each factor is explained with a research hypothesis.

\subsection{Perceived Usefulness}

Perceived usefulness is defined as the extent to which an individual believes that he or she would benefit from using m-banking. Kim et al. argued that an individual often evaluates the consequences of their behavior and makes a choice based on the desirability of perceived usefulness. Therefore, perceived usefulness will influence their intention to accept and adopt a system (Bhatti, 2007; Kim, Chan and Gupta, 2007). In the context of m-banking, one of the reasons people use m-banking is that they find the systems useful to their transactions and saves their time as well. Benefits are also observed by banks in the form of declining the number of branches which reduces the cost per transaction. Numerous studies have shown that perceived usefulness is the primary predictor of information technology usage (Davis, 1989; Davis, Bagozzi and Warshaw, 1989; Gefen, Karahanna and Straub, 2003; Venkatesh and Morris, 2000). This leads to our first hypothesis:

H1: Perceived Usefulness has a positive effect on behavioral intention to adopt m-banking

\subsection{Perceived Ease of Use}

Perceived ease of use is defined as the extent to which an individual believes that using m-banking would be free of effort. Prior studies show that perceived ease of use has a significant effect on usage intention, either directly or indirectly through its effect on perceived usefulness (Davis, 1989; Venkatesh, 2000; Venkatesh and Davis, 1996). A system perceived to be easier to use will facilitate more system use and is more likely to be accepted by uses (Venkatesh and Morris, 2000). In the context of m-banking, customers may find m-banking services uneasy when the system is not easy to learn and easy to use. Information such as details of products or services, their benefits, and usage guidelines needs to be provided as it will make easier for consumers to adopt m-banking. Furthermore, the perceived ease of use helps in building trust with banks as it may send a signal that banks have really put in thought about their end users (Wang, Wang, Lin and Tang, 2003). Thus, we propose the following hypothesis:

H2: Perceived ease of use has a positive effect on behavioral intention to adopt m-banking

\subsection{Perceived Credibility}

Perceived credibility is defined as the extent to which a person believes that using m-banking will be free of security and privacy concerns. One of the biggest risks involved in online/mobile banking is the unwanted disclosure of private information (Fang, Chan, Brzezinski and Xu, 2005; Wang, Wang, Lin and Tang, 2003). Consumers are concerned with risks such as faulty transactions or stolen username and password. And the increased awareness about hackers is another concern. With such high level of ambiguity over the authenticity of information, perception 
of a secure environment that people have in the ability of m-banking to process their transactions securely and to protect the privacy of their personal information is likely to positively affect user's behavioral intention to adopt m-banking (Luarn and Lin, 2005; Rao and Troshani, 2007). Thus, this research proposes the following hypothesis:

H3: Perceived Credibility has a positive effect on behavioral intention to adopt $\mathrm{m}$ - banking

\subsection{Self-Efficacy}

Self-efficacy is defined as the judgment of one's ability, knowledge, or skills to use m-banking services. Social cognitive theory proposes that self-efficacy is the belief that one has the ability to perform a specific behavior (Compeau and Higgins, 1995). An individual with high expertise may have a higher intention to use a system than an individual with lower expertise. Similarly, an individual with high expertise may rate a system as easier to use than an individual who has relatively lower level of expertise. There are numerous studies supporting the influence of self-efficacy on behavioral intentions. For instance, Ellen et al. (1991) indicate that persons perceiving low self-efficacy with a new technology will be more resistant it than persons perceiving high self-efficacy. Also, Luarn and Lin (2005) and Wang et al. (2006) support that self-efficacy has the positive influence on perceived ease of use and the intention to use mobile services. Therefore, we propose the following hypothesis:

H4: Self efficacy has a positive effect on behavioral intention to adopt m-banking

\subsection{Perceived Financial Cost}

Perceived financial resource is defined as the extent to which a person believes that he/she has financial resources needed to use m-banking. Convenience comes at a premium and this is applicable to m-banking as well. To utilize m-banking services, consumers are required to have not only suitable mobile handset but also wireless services. Given that the cost of accessing mobile and wireless service (subscription, service charge, and communication fees) is higher than that of accessing wire-based internet service, financial considerations may influence consumers' behavioral intentions (Kuo and Yen, 2009; Luarn and Lin, 2005; Wu and Wang, 2005). An individual with high financial resources may have higher behavioral intention to use m-banking than an individual with lower financial resources. This leads to our last hypothesis:

H5: Perceived financial cost has a negative effect on behavioral intention to adopt m-banking

\section{Research Methodology}

To validate our proposed model, we used a survey to test consumers' behavioral intention to adopt m-banking. The survey instruments were developed based on a broad literature review (Luarn and Lin, 2005; Pedersen, 2005; Sripalawat, Thongmak and Ngarmyarn, 2011; Wu and Wang, 2005; Yang, 2005) to ensure content validity. The wording was then modified to fit our context of m-banking. The respondents were asked to check the response which best describe their level of agreements with the statements. Each question was measured on a five-point Likert scale, ranging from (1) strongly disagree to (5) strongly agree. The questionnaire was tested extensively for validity before the actual survey was administered. As mentioned above, past operational measures were slightly modified to create the items used in the survey. While the use of previously developed constructs and items helps in developing our survey instruments, it does not ensure validity. As suggested by Peace et al. (2003), iterative review process was undertaken by four IS professionals to maximize content validity and identify ambiguous or poorly worded items. Eighteen items were selected to measure adoption factors and behavioral intention, and were included on the survey instrument in a random order. Few demographic questions were also added at the end of survey.

The instrument was then pilot-tested to identify problems with the instrument's wording, content, format, and procedures. Pilot respondents completed the survey and provided written comments about length, wording, and instructions. Based on the results of the pilot sample, further minor changes were made to the survey design. The full-scale survey was conducted online and offline simultaneously. Participation was entirely voluntary, and the subjects were allocated fifteen minutes to complete the questionnaire. Interactions were not allowed, and confidentiality of responses was emphasized again. In addition, the subjects did not identify themselves on the questionnaires so that they would be truthful in their responses. A number of questionnaires were returned blank or missing relatively large amounts of data. Prior work has demonstrated that missing data can have a significant impact on statistical analyses such as inflated standard errors or biased parameter estimates (Enders, 2004; Finch 2010). Therefore, we decided to drop the incomplete responses rather than using statistical imputations. Of 433 subjects, 165 subjects returned fully completed questionnaires, yielding a response rate of 38.1 percent. Table 2 provides descriptive statistics on the demographic profile of subjects (Please note that some participants did not provide their demographic information. Therefore, the total number of subjects in some items are different from the total number of subjects participated in the survey). 
Table 2. Demographic information on subjects

\begin{tabular}{cccc}
\hline & & Frequency & Percentage \\
\hline \multirow{2}{*}{ M-banking adoption } & Yes & 96 & $58.18 \%$ \\
& No & 69 & $41.82 \%$ \\
Frequency of & Rarely & 35 & $32.71 \%$ \\
M-banking usage & At Times & 39 & $36.45 \%$ \\
& Often & 20 & $18.69 \%$ \\
Gender & Very Often & 13 & $12.15 \%$ \\
& Female & 52 & $31.52 \%$ \\
Age & Male & 113 & $68.48 \%$ \\
& $18-25$ & 35 & $21.21 \%$ \\
& $25-35$ & 96 & $58.18 \%$ \\
& $35-50$ & 25 & $15.15 \%$ \\
Income (SGD) & Above 50 & 9 & $5.45 \%$ \\
& Less than 3,000 & 17 & $10.30 \%$ \\
& $3,001-5,000$ & 43 & $26.06 \%$ \\
& $5,001-10,000$ & 43 & $26.06 \%$ \\
& More than 10,000 & 20 & $12.12 \%$ \\
& Not Applicable & 42 & $25.45 \%$ \\
\hline
\end{tabular}

\section{Data Analysis and Results}

A least square multiple linear regression was used to assess the relationship between predictors among five independent variables and m-banking adoption intention. The results presented in Table 3 indicate that $50.5 \%$ of the variance in behavioral intention to adopt $\mathrm{m}$-banking is explained by the predictors in the model. Perceived usefulness is the most significant factor that positively affects consumers' intention to use m-banking $(\mathrm{r}=0.6291, \mathrm{p}<0.01)$, followed by perceived credibility $(\mathrm{r}=0.1879, \mathrm{p}<0.05)$, self-efficacy $(\mathrm{r}=0.1788, \mathrm{p}<0.05)$, and perceived ease of use $(\mathrm{r}=0.1497, \mathrm{p}<0.10)$. However, perceived financial cost does not an impact on behavioral intention towards m-banking adoption.

Table 3. Results of regression analysis

\begin{tabular}{ccccc}
\hline \multicolumn{5}{c}{ Overall } \\
\hline Hypothesis & Independent variable & r-path coefficient & t-value & Significance \\
H1 & Perceived Usefulness & 0.6291 & $\mathbf{8 . 7 6 6 8}$ & $\boldsymbol{p}<\boldsymbol{0 . 0 1}$ \\
H2 & Perceived Ease of use & 0.1497 & $\mathbf{1 . 7 5 9 9}$ & $\boldsymbol{p}<\boldsymbol{0 . 1 0}$ \\
H3 & Perceived Credibility & 0.1879 & $\mathbf{2 . 0 1 8 1}$ & $\boldsymbol{p}<\boldsymbol{0 . 0 5}$ \\
H4 & Self-Efficacy & 0.1788 & $\mathbf{2 . 4 3 8 5}$ & $\boldsymbol{p}<\boldsymbol{0 . 0 5}$ \\
H5 & Perceived Financial cost & 0.1000 & 1.5841 & N/S \\
\multicolumn{5}{c}{ M-banking users } \\
Hypothesis & Independent variable & r-path coefficient & t-value & Significance \\
H1 & Perceived Usefulness & 0.6205 & $\mathbf{2 . 7 8 3 5}$ & $\boldsymbol{p}<\boldsymbol{0 . 0 1}$ \\
H2 & Perceived Ease of use & 0.2835 & $\mathbf{7 . 0 4 5 0}$ & $\boldsymbol{p}<\boldsymbol{0 . 0 1}$ \\
H3 & Perceived Credibility & 0.1755 & 1.5468 & 0.1254 \\
H4 & Self-Efficacy & 0.1075 & 1.0707 & 0.2872 \\
H5 & Perceived Financial cost & 0.0598 & 0.6948 & 0.4889 \\
M-banking non-users & & \\
Hypothesis & Independent variable & r-path coefficient & t-value & Significance \\
H1 & Perceived Usefulness & 0.6330 & $\mathbf{4 . 8 8 5 6}$ & $\boldsymbol{p}<\boldsymbol{0 . 0 1}$ \\
H2 & Perceived Ease of use & -0.1058 & -0.7341 & 0.4656 \\
H3 & Perceived Credibility & 0.2064 & 1.3458 & 0.1832 \\
H4 & Self-Efficacy & 0.2375 & $\mathbf{2 . 1 7 6 9}$ & $\boldsymbol{p}<\boldsymbol{0 . 0 5}$ \\
H5 & Perceived Financial cost & 0.1013 & 1.0900 & 0.2799 \\
\hline
\end{tabular}


We also compared attitudes of users and non-users toward m-banking adoption. Perceived usefulness is the significant factor for both users $(\mathrm{r}=0.6205, \mathrm{p}<0.05)$ and non-users $(\mathrm{r}=0.6330, \mathrm{p}<0.05)$. For respondents who are currently using m-banking, perceived ease of use has a positive effect on their behavioral intention $(\mathrm{r}=0.2835$, $\mathrm{p}<0.05$ ). However, for respondents who do not use m-banking, perceived ease of use is not a significant factor towards m-banking adoption. We ran the t-test and Mann-Whitney (a non-parametric test for assessing two or more group differences when the distribution is non-normal and/or the equal variance is not assumed), and found that the means of two groups are statistically different from each other $(\mathrm{t}=-1.966, \mathrm{p}<0.05)$. These findings indicate that non-users perceive m-banking to be more difficult to use than those who already have adopted.

Another interesting result is that participants who do not use m-banking believe self-efficacy has the significant effect on their intention to adopt $\mathrm{m}$-banking $(\mathrm{r}=0.2375, \mathrm{p}<0.05)$. However, for respondents who are currently using $\mathrm{m}$-banking, self-efficacy was not a significant factor. This findings support that individuals with higher self-efficacy intent to adopt m-banking more than those with lower self-efficacy. We also ran the t-test and Mann-Whitney to compare two groups, but the mean difference was not statistically significant.

\section{Discussion and Conclusion}

This study examines factors influencing the adoption of m-banking in Singapore. Based on extended TAM model, five factors were identified: perceived usefulness, perceived ease of use, perceived credibility, perceived self-efficacy, and perceived financial cost. Our survey results indicate that perceived usefulness, perceived credibility, self-efficacy and perceived ease of use have a positive influence on consumers' behavioral intention to adopt m-banking.

Perceived usefulness is found to be the most significant factor influencing the intention to use m-banking. This finding suggest that if m-banking is to be accepted by users, they should perceive it as a useful and quicker way of doing banking transactions compared with the traditional banking system. Banking institutions should take advantage of value-adding characteristics of m-banking in promoting perceived usefulness. In addition, they should continue to innovate and invest in m-banking services which allow users to have more alternatives and get more values from m-banking services.

It is interesting to note that our findings are slightly different from other studies. For instance, Luarn and Lin (2005) found that perceived credibility has a stronger influence on behavioral intention than traditional TAM variables (perceived usefulness and ease of use). However, our findings suggest that perceived usefulness is the most significant factor that positively affects consumers' intention to use m-banking. They also showed that perceived financial cost is a significant barrier for users of mobile banking while it is insignificant in our study. These differences indicate that the significance of factors influencing m-baking adoption varies widely across different countries. Therefore, managers should carefully examine cultures, infrastructural conditions, and economic/political conditions prevailing in different regions.

Perceived ease of use has a marginal significance on the intention to adopt $\mathrm{m}$-banking. This finding suggests that consumers seek a simple, easier, faster process and environment for banking transactions. We also showed that perceived ease of use is a major determining factor explaining the attitude difference between adopter and non-adopters toward m-banking. The advent of smart phone has contributed in a rapid growth of m-banking; however there are some inherent drawbacks that come along with a handset. Features like screen size, complicated texting mechanisms, need for high data storage, and shorter battery life seem to be limitations that influence perceived ease of use. Therefore, banks should cooperate with telecommunication companies and mobile manufactures to develop easier to use mobile services by designing phones have features like bigger screen size, convenient keypads and better screen resolutions that encourage the ease of use. Easy operation of a handset in turn could lead to usage of more m-banking services.

Another significant factor affecting the adoption of m-banking is self-efficacy. Therefore, managerial attention should be focused more on developing perceived self-efficacy. When new technologies emerge, people may not utilize them because they perceive it to be difficult to learn. To enhance self-efficacy, banks may initiate training sessions and awareness campaigns on m-banking to help users to get familiar with mobile technologies. Even if these training session and campaigns are not directly related to m-banking services, they can still be helpful to develop more positive usefulness, ease of use, and credibility which in turn can influence to use m-banking. Users may accept and use m-banking because the related information and knowledge guides them to acquire more confidence and to realize increased benefits and convenience by adopting it.

Security and privacy issues are important concerns for consumers in using m-banking services. This implies that bankers and mobile service providers should work together to build trust factors among consumers. Compared with 
Internet banking, security risks could be lower but the susceptibility of device to be lost or stolen is very high. Service providers and mobile handset manufacturers could play a vital role by providing simple traceability solutions within the handset. Suitable authentication mechanisms and increased responsiveness in case of adverse situations could also enhance consumers' perception of security and privacy protection. We highlight different factors influencing the adoption of m-banking services in Figure 1.

Our study has several limitations which creates scope for future researches. First of all, we consider five factors to evaluate behavioral intention towards adopting m-banking. However, additional factors such as innovation, social norm, trust, risk, and facilitating conditions could improve the ability to predict adoption intention more accurately. Furthermore, the structural relationship among constructs and interaction were not considered while we examine the impact of different factors on behavioral intention. With multiple regression analysis, we only evaluate the effect of individual independent variables on the dependent variable. This creates a fairly simple path model, and does not allow for the estimation of mediation, indirect effects, and other complex relationship among variables. A Structural Equation Modeling (SEM) can be introduced to address these issues.

Another limitation of this study is the relatively small sample size (165 subjects). For this reason, caution must be applied as these findings may not be generalized to the broader m-banking adoption based on this study alone. In addition, the findings and implications were derived from a specific user group in Singapore. Therefore, future research is needed to generalize our findings and discussion by including other groups. Lastly, perception of individuals changes over time as they gain experience. Our study measures perceptions and intentions as a single point in time, so it would be interesting to examine long term effects of an individual's acceptance on m-banking. This longitudinal study would provide better understanding of the causality and the interrelationships between variables.

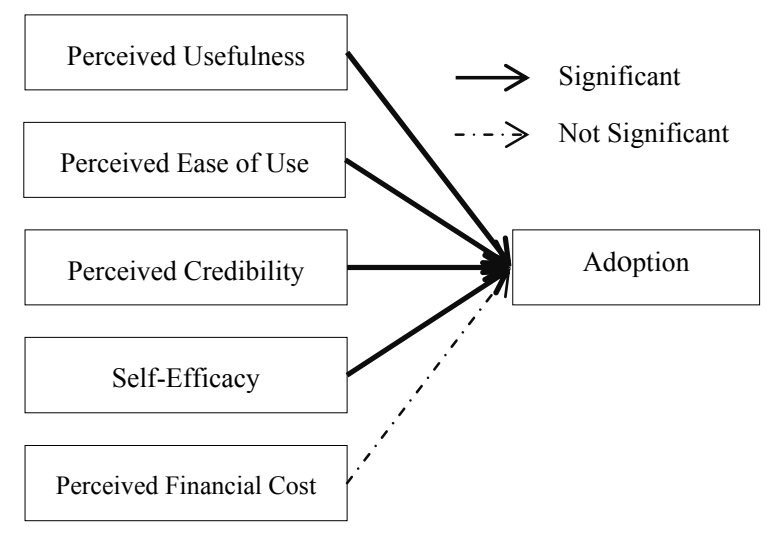

Empirical Evidence: Overall Sample

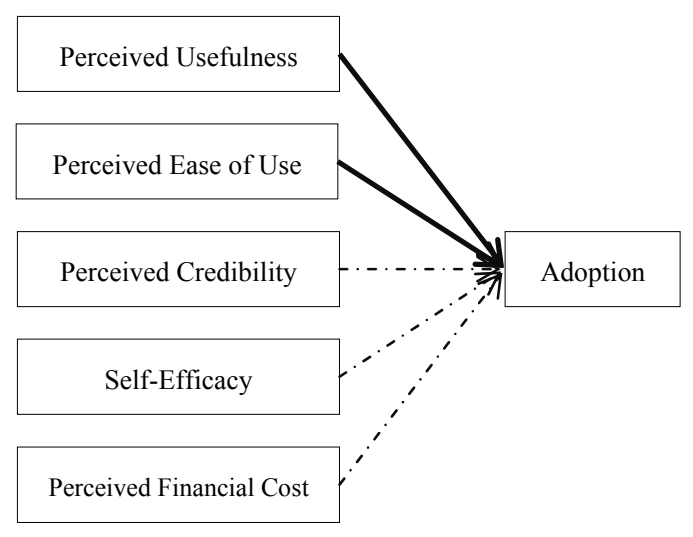

M-banking users



M-banking non-users

Figure 1. Factors influencing the adoption of m-banking services

\section{References}

Bhatti, T. (2007). Exploring Factors Influencing the Adoption of Mobile Commerce. Journal of Internet Banking and 
Commerce, 12(3), 1-13.

Cellular-News, (2011), Mobile Banking Surges as Emerging Markets Embrace Mobile Finance. [Online] Available: http://www.cellular-news.com/story/49148.php (May 12, 2011)

Cheong, J.H., \& Park, M.C. (2008). Mobile Payment Adoption in Korea: Switching from Credit Card. Proceedings of the 15th International Telecommunication Society Europe Regional Conference, 1-22.

Compeau. D.R., \& Higgins, C.A. (1995). Application of Social Cognitive Theory to Training for Computer Skills. Information Systems Research, 6(2), 118-143. http://dx.doi.org/10.1287/isre.6.2.118

Crabbe, M., Standing, M., Standing, C. S., \& Karjaluoto, H. (2009). An Adoption Model for Mobile Banking in Ghana. International Journal of Mobile Communications, 7(5), 515-543. http://dx.doi.org/10.1504/IJMC.2009.024391

Davis, F.D. (1989). Perceived Usefulness, Perceived Ease of Use, and User Acceptance of Information Technology. MIS Quarterly, 13(3), 318-339. http://dx.doi.org/10.2307/249008

Davis, F.D., Bagozzi, R.P., \& Warshaw, P.R. (1989). User Acceptance of Computer Technology: A Comparison of Two Theoretical Models. Management Science, 35(8), 982-1003. http://dx.doi.org/10.1287/mnsc.35.8.982

Donner, J., \& Tellez, C. (2008). Mobile Banking and Economic Development: Linking Adoption, Impact, and Use. Asian Journal of Communication, 18(4), 318-322. http://dx.doi.org/10.1080/01292980802344190

Ellen, P.S., Bearden, W.O., \& Sharma, S. (1991). Resistance to Technological Innovations: An Examination of the Tole of Self-efficacy and Performance Satisfaction. Journal of the Academy of Marketing Science, 19(4), 297-307. http://dx.doi.org/10.1007/BF02726504

Enders, C.K. (2004). The impact of missing data on sample reliability estimates: Implications for reliability reporting practices. Educational and Psychological Measurement, 64 (3), 419-436. http://dx.doi.org/10.1177/0013164403261050

Fang, X., Chan, S., Brzezinski, J., \& Xu, S. (2005). Moderating Effects of Task Type on Wireless Technology Acceptance. Journal of Management Information Systems, 22(3), 123-157. http://dx.doi.org/10.2753/MIS0742-1222220305

Finch, W.H. (2010). Imputation Methods for Missing Categorical Questionnaire Data: A Comparison of Approaches. Journal of Data Science, 8(3), 361-378

Gefen, D., Karahanna, E., \& Straub, D.W. (2003). Trust and TAM in Online Shopping: An Integrated Model. MIS Quarterly, 27(1), 51-90.

Gu, J.C., Lee, S.C., \& Suh, Y.H. (2009). Determinants of Behavioral Intention to Mobile Banking. Expert Systems with Applications, 36(9), 11605-11616. http://dx.doi.org/10.1016/j.eswa.2009.03.024

Horton, R.P., Buck, T., Waterson, P.E., \& Clegg, C.W. (2001). Explaining Intranet Use with the Technology Acceptance Model. Journal of Information Technology, 16(4), 237-249. http://dx.doi.org/10.1080/02683960110102407

Infocomm Development Authority of Singapore, (2011), Statistics on Telecom Services for 2011. [Online] Available: http://www.ida.gov.sg/Publications/20061205165739.aspx (October, 2011)

Kim, G., Shin, B., \& Lee, H.G. (2009). Understanding Dynamics between Initial Trust and Usage Intentions of Mobile Banking. Information Systems Journal, 19 (3), 283-311. http://dx.doi.org/10.1111/j.1365-2575.2007.00269.x

Kim, H.W., Chan, H.C., \& Gupta, S. (2007). Value-based Adoption of Mobile Internet: An Empirical Investigation. Decision Support Systems, 43(1), 111-126. http://dx.doi.org/10.1016/j.dss.2005.05.009

Kleijnen, M., Wetzels, M., \& Ruyter, K.D. (2004). Consumer Acceptance of Wireless Finance. Journal of Financial Services Marketing, 8(3), 206-217. http://dx.doi.org/10.1057/palgrave.fsm.4770120

Kuo, Y.F., \& Yen, S.N. (2009). Towards an Understanding of the Behavioral Intention to Use 3G Mobile Value-added Services. Computers in Human Behavior, 25(1), 103-110. http://dx.doi.org/10.1016/j.chb.2008.07.007

Laforet, S., \& Li, X. (2005). Consumers' Attitudes toward Online and Mobile Banking in China. International Journal of Bank Marketing, 23(5), 362-380. http://dx.doi.org/10.1108/02652320510629250

Lederer, A.L., Maupin, D.J., Sena, M.P., \& Zhuang, Y.L. (2000). The Technology Acceptance Model and the World Wide Web. Decision Support System, 29(3), 269-282. http://dx.doi.org/10.1016/S0167-9236(00)00076-2

Luarn, P., \& Lin, H.H. (2005). Toward an Understanding of the Behavioral Intention to Use Mobile Banking. 
Computers in Human Behavior, 21(6), 873-891. http://dx.doi.org/10.1016/j.chb.2004.03.003

Luo, X., Li, H., Zhang, J., \& Shim, J.P. (2010). Examining Multi-dimensional Trust and Multi-faceted Risk in Initial Acceptance of Emerging Technologies: An Empirical Study of Mobile Banking Services. Decision Support Systems, 49(2), 222-234. http://dx.doi.org/10.1016/j.dss.2010.02.008

Mathieson, K., Peacock, E., \& Chin, W.W. (2001). Extending the Technology Acceptance Model: The Influence of Perceived User Resources. The DATA BASE for Advances in Information Systems, 32(3), 86-112. http://dx.doi.org/10.1145/506724.506730

Mattila, M. (2003). Factors Affecting The Adoption Of Mobile Banking Services. Journal of Internet Banking and Commerce, 8(1), 149-160.

Pavlou, P.A. (2003). Consumer Acceptance of Electronic Commerce: Integrating Trust and Risk with the Technology Acceptance Model. International Journal of Electronic Commerce, 7(3), 101-134.

Peace, A.G., Galletta, D.F., \& Thong, J.Y.L. (2003). Software Piracy in the Workplace: A Model and Empirical Test. Journal of Management Information Systems, 20(1), 153-177.

Pedersen, P.E. (2005). Adoption of Mobile Internet Services: An Exploratory Study of Mobile Commerce Early Adopters. Journal of Organizational Computing and Electronic Commerce, 15(3), 203-222. http://dx.doi.org/10.1207/s15327744joce1503_2

Rao, S., \& Troshani, I. (2007). A Conceptual Framework and Propositions for the Acceptance of Mobile Services. Journal of Theoretical and Applied Electronic Commerce Research, 2(2), 61-73.

Riquelme, H.E., \& Rios, R.E. (2010). The Moderating Effect of Gender in the Adoption of Mobile Banking. International Journal of Bank Marketing, 28(5), 328-341. http://dx.doi.org/10.1108/02652321011064872

Sripalawat, J., Thongmak, A., \& Ngramyarn A. (2011). M-banking in Metropolitan Bangkok and a Comparison with Other Countries. Journal of Computer Information Systems, 51(3), 67-76.

Suoranta, M., \& Mattila, M. (2004). Mobile Banking and Consumer Behaviour: New Insights into the Diffusion Pattern. Journal of Financial Services Marketing, 8(4), 354-366. http://dx.doi.org/10.1057/palgrave.fsm.4770132

Venkatesh, V. (2000). Determinants of Perceived Ease of Use: Integrating Control, Intrinsic Motivation, and Emotion into the Technology Acceptance Model. Information Systems Research, 11(4), 342-365. http://dx.doi.org/10.1287/isre.11.4.342.11872

Venkatesh, V., \& Davis, F.D. (1996). A Model of the Antecedents of Perceived Ease of Use: Development and Test. Decision Sciences, 27(3), 451-481. http://dx.doi.org/10.1111/j.1540-5915.1996.tb01822.x

Venkatesh, V., \& Davis, F.D. (2000). A Theoretical Extension of the Technology Acceptance Model: Four Longitudinal Field Studies. Management Science, 46(2), 186-204. http://dx.doi.org/10.1287/mnsc.46.2.186.11926

Venkatesh, V., \& Morris, M.G. (2000). Why Don't Men Ever Stop to Aask for Directions? Gender, Social Influence, and Their Role in Technology Acceptance and Usage Behavior. MIS Quarterly, 24(1), 115-139. http://dx.doi.org/10.2307/3250981

Wang, Y.S., Wang, Y.M., Lin, H.H., \& Tang, T.I. (2003). Determinants of User Acceptance of Internet Banking: An Empirical Study. International Journal of Service Industry Management, 14(5), 501-519. http://dx.doi.org/10.1108/09564230310500192

Wang, Y.S., Lin, H.H., \& Luarn, P. (2006). Predicting Consumer Intention to Use Mobile Service. Information Systems Journal, 16(2), 157-179. http://dx.doi.org/10.1111/j.1365-2575.2006.00213.x

Wilcox, Howard, (2010), Mobile Banking Goes Mainstream. [Online] Available: http:/juniperresearch.com/shop/products/whitepaper/pdf/Mobile\%20Banking\%20WP\%202010.pdf (June, 2010)

Wu, J.H., \& Wang, S.C. (2005). What Drives Mobile Commerce?: An Empirical Evaluation of the Revised Technology Acceptance Model. Information \& Management, 42(5), 719-729. http://dx.doi.org/10.1016/j.im.2004.07.001

Yang, K.C.C. (2005). Exploring Factors Affecting the Adoption of Mobile Commerce in Singapore. Telematics and Informatics, 22(3), 257-277. http://dx.doi.org/10.1016/j.tele.2004.11.003 